\title{
Statins and the vasculopathy of systemic sclerosis: potential therapeutic agents?
}

Chris T. Derk

Thomas Jefferson University

Sergio A. Jimenez

Thomas Jefferson University

Follow this and additional works at: https://jdc.jefferson.edu/medfp

Part of the Rheumatology Commons

Let us know how access to this document benefits you

\section{Recommended Citation}

Derk, Chris T. and Jimenez, Sergio A., "Statins and the vasculopathy of systemic sclerosis: potential therapeutic agents?" (2006). Department of Medicine Faculty Papers. Paper 206. https://jdc.jefferson.edu/medfp/206

This Article is brought to you for free and open access by the Jefferson Digital Commons. The Jefferson Digital Commons is a service of Thomas Jefferson University's Center for Teaching and Learning (CTL). The Commons is a showcase for Jefferson books and journals, peer-reviewed scholarly publications, unique historical collections from the University archives, and teaching tools. The Jefferson Digital Commons allows researchers and interested readers anywhere in the world to learn about and keep up to date with Jefferson scholarship. This article has been accepted for inclusion in Department of Medicine Faculty Papers by an authorized administrator of the Jefferson Digital Commons. For more information, please contact: JeffersonDigitalCommons@jefferson.edu. 


\title{
STATINS AND THE VASCULOPATHY OF SYSTEMIC SCLEROSIS: POTENTIAL THERAPEUTIC AGENTS?
}

\author{
Chris T. Derk and Sergio A. Jimenez \\ Division of Rheumatology, Department of Medicine \\ Thomas Jefferson University, Philadelphia, PA 19107, USA
}

C.T. Derk, Assistant Professor of Medicine; S.A. Jimenez, Professor of Medicine and Professor of Biochemistry and Molecular Pharmacology.

Grant Support: By National Institutes of Health Grant AR19616 (SAJ).

Key words: Systemic sclerosis, statins, vasculopathy, tissue fibrosis, Raynaud's phenomenon.

Address all correspondence to:

Chris T. Derk, M.D.

Division of Rheumatology

Thomas Jefferson University

613 Curtis Bldg, 1015 Walnut Street

Philadelphia, PA 19107-5541, USA

Tel: 215-955-1410

E-mail: $\underline{\text { Chris.Derk@jefferson.edu }}$ 


\section{ABSTRACT}

It has been postulated that endothelial cell injury is the initiating event in the pathogenesis of systemic sclerosis, causing attraction, attachment, migration and infiltration of activated T cells and subsequent production of cytokines and growth factors. As a result of the action of these cytokines and growth factors, chemoattraction of fibroblasts into the vessel wall and trans-differentiation of resident fibroblasts and smooth muscle cells into myofibroblasts occurs leading to fibrosis and exaggerated collagen deposition in the vessel wall. The vascular fibroproliferative lesion in systemic sclerosis is frequently accompanied by severe vasomotor instability manifested clinically by the occurrence of Raynaud's phenomenon, as well as, by an exaggerated vasoconstrictor response in the visceral microvasculature, particularly, in the kidneys, the lungs, and the myocardium. The fibroproliferative vascular occlusion coupled with the vasospastic response causes hypoxia and additional endothelial injury propagating further the vascular fibrotic lesion. To date, the therapeutic options for the vasculopathy of systemic sclerosis have been limited to drugs that cause vasodilation and inhibit platelet aggregation and only a few agents have shown vascular remodeling effects. Therapeutic agents which could potentially modify the course of this vasculopathy may have a disease modifying effect, particularly, if instituted in the early stages of the disease.

Extensive recent studies have shown that statins display numerous effects independent of their well established lipid-lowering effect that may be of potential benefit in preventing vascular injury and ischemic vascular events. These effects may both prevent and improve vessel wall abnormalities, as well as, cause a local increase in the production and secretion of vasodilating molecules. Here, we review the current 
literature to provide support of a testable hypothesis that postulates that statins may have a modifying effect on the vasculopathy of systemic sclerosis.

\section{INTRODUCTION}

Vascular dysfunction and structural vessel wall abnormalities appear to be among the earliest alterations in systemic sclerosis. Indeed, it has been suggested that endothelial cell and vascular injury may be the crucial initiating event in the pathogenesis of this disorder $(1,2)$. Endothelial dysfunction is one of three fundamental abnormalities characteristic of systemic sclerosis; the others being tissue fibrosis caused largely by increased collagen gene expression in dermal and visceral fibroblasts, and alterations in humoral and cell mediated immunity (3). The profound functional endothelial cell alterations in systemic sclerosis result in the progressive obliteration of the lumen of small arterioles and capillaries by newly formed fibrotic tissue causing a severe vasculopathy which most commonly involves the microvascular system. The most common clinical manifestation of this unique vasculopathy is the occurrence of Raynaud's phenomenon with narrowing and eventual occlusion of digital vessels. However, visceral organs such as the kidneys, lungs, heart and skeletal muscle are also frequently involved (4).

Smooth muscle cells in the intimal layer of the vessel wall become activated likely owing to their transdifferentiation into myofibroblasts, migratory cells which characteristically display a marked increase in collagen production, causing an exaggerated deposition of collagen and other extracellular matrix macromolecules in the tissue. This fibroproliferative lesion coupled with the exaggerated vasoconstrictive 
vascular response typical of systemic sclerosis causes chronic hypoxia that leads to further endothelial injury and fibrosis. The severe vasomotor instability in these vessels is caused by $\alpha_{2 c}$ adrenergic hyperactivity, the local overproduction of vasoconstrictive substances such as endothelin, and the reduced production of local vasodilating agents such as NO. The narrowing of the vessel lumen and the endothelial dysfunction further propagate tissue ischemia by inducing platelet aggregation and local thrombosis $(3,4)$.

Therapy for the vasculopathy of systemic sclerosis has included vasodilator agents such as calcium channel blockers, prostaglandins, phosphodiesterase inhibitors, endothelin receptor inhibitors, and agents causing increased NO production such as nitroglycerin (5), as well as, antiplatelet agents to prevent thrombotic vessel occlusion and platelet aggregation. Some of these agents such as angiotensin converting enzyme inhibitors, angiotensin receptor blockers, prostaglandins and endothelin receptor inhibitors have also been shown to cause some vascular remodeling and improvement of the intimal fibrotic lesion. In this regard, it is of substantial interest that recent studies have suggested that the statins may also interfere with the pathological changes in the vessel wall $(6,7)$. It is well established that suppression of elevated total and low density lipoprotein cholesterol levels by statins promotes primary and secondary prevention of ischemic, atherosclerotic related events in patients with hypercholesterolemia (8-13). This effect was initially believed to be solely related to the cholesterol lowering effects of the statins, however, there is increasing evidence that these agents may exert profound endothelial and vascular protective effects beyond their lipid lowering action (14-16). Indeed, experimental studies have shown that statins 
protect normocholesterolemic animals from the development of myocardial infarction (17).

These later clinical and experimental observations have led to a wealth of research studies examining the pleiotropic effects of statins including modification of vascular pathology and have allowed the suggestion that these agents may have beneficial effects in other diseases accompanied by vasculopathy. In order to understand these pleiotropic effects, it is necessary to understand the metabolic pathways upon which these agents exert their cholesterol lowering effect. Statins inhibit the 3-hydroxy-3 methylglutanyl coenzyme A (HMG-CoA) reductase, the enzyme which catalyzes the formation of mevalonate from HMG-CoA, the earliest step in the production of cholesterol (Figure1). As can be seen in the diagram, mevalonate is also the precursor of isoprenoid groups which are required to modify post-translationally the Rho and Ras-superfamilies of proteins by attaching a hydrophilic prenyl group, either farnesyl or geranylgeranyl. The Rho and Ras proteins are small membrane-bound GTPases, which are active in the GTPbound state and inactive in the GDP-bound state. In their active state these proteins regulate important cellular functions including cell survival, proliferation and differentiation, as well as, cytoskeletal organization, by relaying extracellular ligandstimulated signals to cytoplasmic signaling cascades. It is the inhibition of prenylation of the Rho and Ras-related proteins by statins that is postulated to be responsible for some of the pleiotropic effects of this class of agents (18-21). 


\section{Making a Case for Statin Use in Systemic Sclerosis Vasculopathy}

Statins as immune modulating agents. As described above, endothelial injury and the development of a vasculopathy have been postulated to be the initial pathogenic events in the development of systemic sclerosis. Endothelial injury which in some cases may be augmented by circulating antiendothelial antibodies (22), leads to attraction, attachment, migration and local infiltration of activated $\mathrm{T}$ cells. Tissue infiltrating T-cells initiate local production of cytokines and growth factors. The locally produced cytokines and growth factors may cause additional chemoattraction of fibroblasts, as well as, the transdifferentiation of tissue bound fibroblasts and smooth muscle cells in the vascular wall into myofibroblasts, cells with migratory abilities as well as increased capacity to produce collagen and other extracellular matrix components. Modulation of the function of tissue infiltrating T-cells at this stage could, thus, prevent or modify the vasculopathic process of systemic sclerosis. Some studies have suggested that statins could influence favorably these early events as indicated by investigations in the transplantation field showing that patients treated with statins were less likely to reject or to develop vasculopathy of the transplanted organ $(23,24)$. The mechanisms by which the statins can cause these effects are multiple. For example, statins have been shown to downregulate the expression of numerous adhesion molecules on endothelial cells and lymphocytes, including monocyte chemotactic protein-1 (MAC-1 also known as $\alpha \mathrm{M}-\beta 2$ or CD11b/CD18) $(25,26)$, intercellular adhesion molecule-1 (ICAM-1 or CD54) (27), and lymphocyte function associated antigen-1 (LFA-1 or CD11a/CD18 or $\alpha \mathrm{L}-\beta 2$ ). Statins also interfere with the interaction between ICAM- 1 and LFA- 1 by binding to the LFA-1 L-site which is involved in the activation of lymphocytes by antigen presenting cells 
(APC) $(28,29)$ (Figure 2). These effects inhibit the flux of lymphocytes into the sites of inflammation, which in turn leads to a decreased local production of cytokines and growth factors. Furthermore, statins have been shown to inhibit the inducible expression of major histocompatibility complex class II (MHC II) in specialized antigen presenting cells (APC) such as dendritic cells, macrophages and B lymphocytes (30,31), thus, reducing antigen presentation to T-cells.

The pleiotropic effects of statins on immune cells including inhibition of lymphocyte activation by blocking antigen presentation, reduction of lymphocyte proliferation, and reduction of cytokine and growth factor expression suggest that these agents may exert novel therapeutic effects on immunologically mediated disorders. While it would be naïve to assume that the favorable results obtained in in vitro studies will correlate with similarly favorable effects in vivo, nonetheless clinical studies have focused on the potential use of statins in autoimmune mediated disorders, and early results in rheumatoid arthritis, antiphospholipid antibody syndrome, inflammatory arthritis, autoimmune encephalomyelitis and multiple sclerosis appear promising (32-35). In relation to systemic sclerosis, an upregulation of MHC II complex, MCP-1 and ICAM-1 has already been described in fibroblasts and endothelial cells, especially early in the disease process. These events appear to be necessary for the influx of fibroblasts and inflammatory cells into the vessel wall and the subsequent vessel wall fibrotic changes (36). The newly recognized effects of statins on the chemokines mentioned above may therefore inhibit the progression of the vasculopathy of systemic sclerosis and modify the disease. Furthermore, interference with the ICAM-1-LFA-1 interaction may downregulate local inflammation and cytokine production. 
Statins as vasodilators. A fundamental alteration in systemic sclerosis is the dysfunction or dysregulation of vascular tone in favor of a vasoconstricting response. The inherent damage to the endothelial cells which is believed to be one of the intial events in the pathogenesis of this vasculopathy leads to an increased ratio of endothelial derived vasoconstricting agents, such as endothelin and angiotensin II, as compared to endothelial derived vasodilating agents such as $\mathrm{NO}$ and prostacyclin. A similar imbalance has also been postulated between vasoconstricting and vasodilating neuromediators. The predominant production of vasoconstricting molecules coupled with the exaggerated neurogenic vasoconstrictor response lead to further tissue ischemia and propagation of the disease process.

The production of nitric oxide, the most important endothelium derived vasodilating agent, is downregulated in systemic sclerosis owing to endothelial dysfunction (Figure 2). Besides its vasodilating effects, $\mathrm{NO}$ also inhibits platelet aggregation and adhesion, decreases endothelium permeability and local inflammatory cytokine production, and interferes with the adhesion of macrophages and leukocytes to the endothelium (37-40). Thus, an increased production of $\mathrm{NO}$ would be expected to improve the vasculopathy of systemic sclerosis by modifying favorably several pathogenic events. Recent evidence has demonstrated that statins are capable of increasing NO production by causing an upregulation of endothelial derived nitric oxide synthase (eNOS); this effect is detectable as early as two weeks following the initiation of statin therapy and is mediated through two separate pathways. One of these pathways is the stabilization of eNOS transcripts. This effect appears to be mediated by inhibition of protein prenylation reactions by the statins. Statins, as stated previously, do not only 
inhibit cholesterol synthesis but also prevent farnesyl and geranylgeranyl prenylation of numerous molecules including members of the Rho and Ras-superfamilies of proteins (Figure 1). The observation that the addition of geranyl geranyl pyrophosphate (GGPP) reverses in vitro the upregulation of eNOS expression induced by statins, whereas, addition of farnesyl pyrophosphate fails to reverse this effect suggests that geranylgeranyl synthesis and the geranylation of RhoA are directly related to the expression of eNOS. The second pathway by which statins appear to have an effect on eNOS is through the activation of the phosphatidylinositol (PI)-3-kinase/ protein kinase $\mathrm{B}(\mathrm{Akt})$ pathway since it has been shown that the serine-threonine protein kinase Akt phosphorylates and activates eNOS (41-44).

Endothelin-1 (ET-1) is a potent endothelium derived vasoconstrictor protein which appears to play an important role in the pathogenesis of systemic sclerosis (Figure 2). The recent development of specific endothelin receptor blockers has shown that inhibition of ET-1 may be an effective therapy for the pulmonary arterial hypertension of systemic sclerosis. This approach also appears promising for the peripheral vasculopathy and the interstitial lung involvement of this disorder (45). Statins have two effects on the ET-1 pathway. On the one hand, it has been shown that statins reduce pre-pro ET-1 mRNA expression, an effect which appears to be mediated by the inhibition of geranylgeranyl prenylation of RhoA $(46,47)$. A second mechanism appears to be the decrease in the expression of endothelin receptors in vascular cells (48).

Recent work also has shown that both cerivastatin and fluvastatin downregulate endothelial angiotensin II type I receptors, an effect also mediated by inhibition of 
prenylation of RhoA, thus potentially inhibiting the vasoconstrictive effect of angiotensin II (49).

Statins as antifibrotic agents. Tissue fibrosis is the most prominent clinical manifestation of systemic sclerosis and is caused by the exaggerated accumulation of types I and III collagens and other connective tissue components in the extracellular matrix. Growth factors that play central roles in this process are transforming growth factor- $\beta 1$ (TGF- $\beta 1$ ) and connective tissue growth factor (CTGF) $(3,50)$ (Fig 2). Statins have been shown to downregulate the expression of TGF- $\beta 1$ by renal mesangial cells in models of renal nephropathy in which fibrosis is mediated by TGF- $\beta 1$ and CTGF (51, 52). Furthermore, statins cause potent reduction of CTGF mRNA levels in normal human and rodent mesangial cell lines, as well as, in human renal fibroblast cell lines, an effect also mediated by a decrease in geranylgeranyl prenylation of RhoA (53-55).

As part of the initiating events of any fibrotic disorder there is a proliferation or preferential selection of cells that have a profibrotic potential and/or transdifferentiation of cells with low extracellular matrix production capacity to cells with a much higher biosynthetic activity for molecules involved in the fibrotic process. The mesangial cells play this central role in diabetic nephropathy and other fibrotic nephropathies, whereas, in hepatic fibrosis and pulmonary fibrosis, the responsible cells are the stellate cells and the lung myofibroblasts, respectively. Statins have been shown in in vitro models of these fibrotic disorders to inhibit the proliferation of cells involved in the fibrotic process causing their increased apoptosis, as well as, causing a decrease in their production of extracellular matrix components. These results suggest that statins may also have a beneficial effect in various fibroproliferative disorders (56-58). 
Some studies have examined the effects of statins on cells from diseases associated with tissue fibrosis, however, only a few studied cells from patients with systemic sclerosis. In a recent in vitro study employing systemic sclerosis skin fibroblasts, we showed that GGTI-296, a specific inhibitor of geranylgeranyl transferase 1(GGT1) causes a potent inhibition (up to $80 \%$ ) of the expression of genes encoding types I and III collagens (59). This study suggested that inhibition of geranyl-geranyl prenylation by statins may also have similar effects to those of GGTI-296 on expression of collagen genes in systemic sclerosis fibroblasts. We therefore examined the in vitro effects of lovastatin and simvastatin on collagen production and type I collagen mRNA levels in cultured normal and systemic sclerosis dermal fibroblasts. We found that, indeed, both drugs were potent inhibitors of collagen production and caused a substantial reduction of collagen gene expression in these cells (60). In agreement with these results, another study showed that atorvastatin inhibited in a dose dependent manner ICAM-1 expression on systemic sclerosis fibroblasts and reduced type I collagen production in both systemic sclerosis and normal fibroblasts (61).

Other statin effects. Besides the immunomodulatory, vasodilating and antifibrotic effects discussed above, statins may also have antithrombotic and fibrinolytic effects by decreasing PAI- 1 and increasing t-PA expression $(62,63)$ and may inhibit vascular smooth muscle cell proliferation (64), decrease the release of reactive oxygen species (65), inhibit platelet function (66) and increase prostacyclin production from both endothelial and vascular smooth muscle cells (67) (Figure 2). These additional effects may also be of substantial value to improve the vasculopathy of systemic sclerosis. 


\section{CONCLUSION}

It has recently been recognized that statins display a remarkable array of important biological effects besides their well known cholesterol lowering effects. It has also become recognized that most of these pleiotropic effects appear to be mediated through the inhibition of protein prenylation. Protein prenylation results from the posttranslational covalent attachment of geranyl-geranyl or farnesyl groups into various proteins. Protein prenylation causes crucial modifications of the function of target proteins including the activation of enzymatic or phosphorylation domains. The Rho and Ras superfamilies of proteins are important targets for prenylation. It has been hypothesized that these proteins modify the structure and function of cells in the vessel wall in manners that may prevent ischemic or proliferative vascular events. However, it should be emphasized that not all statins possess this vast array of pleiotropic effects and that there are substantial differences among the statins in relation to the prenylation of Rho and Ras superfamilies of proteins in endothelial cells. Extensive studies have shown that only hydrophobic statins have the ability to enter the endothelial cells and inhibit the mevalonate pathway.

The remarkable modulation by statins of such diverse pathogenic cascades such as those involved in immune mediated inflammatory reactions, vascular tone regulation, production of increased levels of NO, and regulation of collagen gene expression have provided a cogent rationale for the use of statins in disorders other than those related to hypercholesterolemic and atherosclerotic disease. Indeed, some recent studies have examined the disease modifying effects of statins in disorders such as rheumatoid arthritis (34) and multiple sclerosis (35). The vascular modifying effects discussed briefly here 
provide strong support to the testable hypothesis that statins may be of benefit in the treatment of the vasculopathy of systemic sclerosis and suggest that it may prove rewarding to investigate these effects in pre-clinical and clinical studies for systemic sclerosis, a disease in which the prominent endothelial cell dysfunction and vascular abnormalities have been suggested to play a crucial role in its pathogenesis and evolution.

Thus, we posit here that in systemic sclerosis, a disease for which few proven disease modifying agents are available, statins, which are readily available and have been demonstrated to be remarkably safe, are a promising alternative which deserves further studies. 


\section{REFERENCES}

1. Campbell PM, LeRoy EC. Pathogenesis of systemic sclerosis: a vascular hypothesis.Semin Arthritis Rheum 1975;4: 351-68.

2. LeRoy EC. Systemic sclerosis: A vascular perspective. Rheum Dis Clin N Am 1996;22: 695-708.

3. Jimenez SA, Derk CT. Following the molecular pathways toward an understanding of the pathogenesis of systemic sclerosis. Ann Intern Med 2004;140: 37-50.

4. Guiducci S, Pignone A, Matucci-Cerinic M. Raynaud's phenomenon in systemic sclerosis. In: Clements PJ, Furst DE. Systemic Sclerosis. Philadelphia, PA: Lippincott Williams and Wilkins, 2004; 221-239.

5. Hummers LK, Wigley FM. Management of Raynaud's phenomenon and digital ischemic lesions in scleroderma. Rheum Dis Clin North Am 2003;29: 293-313.

6. Sule SD, Wigley FM. Treatment of scleroderma: an update. Expert Opin Investig Drugs 2003;12: 471-82.

7. Shor R, Halabe A. New trends in the treatment of scleroderma renal crisis. Nephron 2002;92: 716-8.

8. Lipid Research Clinics Program: The Lipid Research Clinics Coronary Prevention Trial results II: The relationship of reduction in incidence of coronary heart disease to cholesterol lowering. JAMA 1984;251: 365-74.

9. West of Scotland Coronary Prevention Study Group: Baseline risk factors and their association with outcome in the West of Scotland Coronary Prevention Study. Am J Cardiol 1997;79: 756-62. 
10. Downs JR, Clearfield M, Weis S, et al. for the AFCAPS/TexCAPS Research Group: Primary prevention of acute coronary events with lovastatin in men and women with average cholesterol levels: Results of AFCAPS/TexCAPS. JAMA 1998; 279: 1615-22.

11. Scandinavian Simvastatin Survival Study Group: Randomized trial of cholesterol lowering in 4444 patients with coronary heart disease: The Scandinavian Simvastatin Survival Study(4S). Lancet 1994;344: 1383-89.

12. Heart Protection Study Collaborative Group: MRC/BHF Heart Protection Study of cholesterol lowering with simvastatin in 20536 high-risk individuals: A randomized controlled trial. Lancet 2002; 360: 1623-30.

13. The ALLHAT Officers and Coordinators for the ALLHAT Collaborative Research Group: Major outcomes in moderately hypercholesterolemic, hypertensive patients randomized to pravastatin vs. usual care. JAMA 2002;288: 2998-3007.

14. Jukema JW, Bruschke AVG, van Boven AJ, et al. Effects of lipid lowering by pravastatin on progression and regression of coronary artery disease in symptomatic men with normal to moderately elevated serum cholesterol levels: The Regression Growth Evaluation Statin Study (REGRESS). Circulation 1995;91: 2528-40.

15. Sacks FM, Pfeffer MA, Moye LA, et al. The effect of pravastatin on coronary events after myocardial infarction in patients with average cholesterol levels: Cholesterol and Recurrent Events Trial Investigators. N Engl J Med 1996; 335 : $1001-9$. 
16. Pekkanen J, Linn S, Heis G, et al. Ten-year mortality from cardiovascular disease in relation to cholesterol level among men with and without pre-existing cardiovascular disease. N Engl J Med 1990; 322: 1700-7.

17. Lefer AM, Campbell B, Shin YK, et al. Simvastatin preserves the ischemicreperfused myocardium in normocholesterolemic rat hearts. Circulation 1999;100: $178-84$.

18. Holstein SA, Wohlford-Lenane CL, Hohl RJ. Isoprenoids influence expression of Ras and Ras-related proteins. Biochem 2002;41: 13698-704.

19. Goldstein JL, Brown MS. Regulation of the mevalonate pathway. Nature 1990;343: 425-30.

20. Vojtek AB, Der CJ. Increasing complexity of the Ras signaling pathway. J Biol Chem 1998;273: 19925-928.

21. Holstein SA, Wohlford-Lenane CL, Hohl RJ. Consequences of mevaloante depletion. J Biol Chem 2002;277: 10678-682.

22. Sgonce R, Gruschwitz MS, Boeck G, et al. Endothelial cell apoptosis in systemic sclerosis is induced by antibody-dependent cell-mediated cytotoxicity via CD95. Arthritis Rheum 2000;43: 2550-62.

23. Kobashigawa JA, Katznelson S, Laks H, et al. Effect of pravastatin on outcomes after cardiac transplantation. N Engl J Med 2995;333: 621-27.

24. Katznelson S, Wilkinson AH, Kobashigawa JA, et al. Transplantation 1996;61: 1469-74.

25. Rezaie-Majd A, Maca T, Bucek RA, et al. Simvastatin reduces expression of cytokines interleukin-6, interleukin-8, and monocyte chemoattractant protein-1 in 
circulating monocytes from hypercholesterolemic patients. Arterioscler Thromb Vasc Biol 2002;22: 1194-99.

26. Kowalski J, Okopien B, Madej A, et al. Effects of atrovastatin, simvastatin and fenofibrate therapy on monocyte chemoattractant protein-1 secretion in patients with hyperlipedemia. Eur J Clin Pharmacol 2003;59: 198-93.

27. Zapolska-Downar D, Siennicka A, Kaczmarczyk M, et al. Simvastatin modulates TNF- $\alpha$ induced adhesion molecules expression in human endothelial cells. Life Sci 2004;75: 1287-1302.

28. Frenette PS. Locking a leukocyte integrin with statins. N Engl J Med 2001; 345: 1419-21.

29. Weitz-Schmidt G, Welzenbach K, Brinkmann V, et al. Statins selectively inhibit leukocyte function antigen-1 by binding to a novel regulatory integrin site. Nat Med 2001;7: 687-92.

30. Kwak B, Mulhaupt F, Myit S, et al. Statins as a newly recognized type of immunomodulator. Nat Med 2000;6: 1399-1402.

31. Mach F. Statins as immunomodulatory agents. Circulation 2004;109(21 Suppl 1): II15-7.

32. Youssef S, Stuve O, Patarroyo JC, et al. The HMG-CoA reducatse inhibitor, atorvastatin, promotes a Th2 bias and reverses paralysis in central nervous system autoimmune disease. Nature 2002;420: 78-84.

33. Leung BP, Sattar N, Crilly A, et al. A novel anti-inflammatory role for simvastatin in inflammatory arthritis. J Immunol 2003;170: 1524-30. 
34. McCarey DW, McInnes IB, Madhok R, et al. Trial of atorvastatin in rheumatoid arthritis (TARA): double blind, randomized-controlled trial. Lancet 2004;363: 2015-21.

35. Vollmer T, Key L, Durkalski V, et al. Oral simvastatin treatment in relapsingremitting multiple sclerosis. Lancet 2004;363: 1607-8.

36. Atamas SP. Complex cytokine regulation of tissue fibrosis. Life Sci 2002;72: 63143.

37. De Caterina R, Libby P, Peng HB, et al. Nitric oxide decreases cytokine-induced endothelial activation. Nitric oxide selectively reduces endothelial expression of adhesion molecules and proinflammatory cytokines. J Clin Invest 1995;96: 60-8.

38. Gauthier TW, Scalia R, Murohara T, et al. Nitric oxide protects against leukocyteendothelium interactions in the early stages of hypercholesterolemia. Arterioscler Thromb Vasc Biol 1995;15: 1652-9.

39. Radomski MW, Moncada S. Regulation of vascular homeostasis by nitric oxide. Thromb Haemost 1993;70: 36-41.

40. Ross R. Atherosclerosis-an inflammatory disease. N Engl J Med 1999;340:115-26.

41. John S, Delles C, Jacobi J, et al. Rapid improvement of nitric-oxide bioavailability after lipid-lowering therapy with cerivastatin within two weeks. J Am Coll Cardiol 2001;37: 1351-8.

42. Laufs U, La Fata V, Plutzky J, et al. Upregulation of endothelial nitric oxide synthase by HMG CoA reductase inhibitors. Circulation 1998;97: 1129-35. 
43. Kalinowski L, Dobrucki IT, Malinski T. Cerivastatin potentiates nitric oxide release and ENOS expression through inhibition of isoprenoids synthesis. J Phys Pharm 2002;5: 585-95.

44. Kureishi Y, Luo Z, Shiojima I, et al. The HMG-CoA reductase inhibitor simvastatin activates the protein kinase Akt and promotes angiogenesis in normocholesterolemic animals. Nat Med 200;6: 1004-10.

45. Hachulla E, Coghlan JG. A new era in the management of pulmonary arterial hypertension related to scleroderma: endothelin receptor antagonism. Ann Rheum Dis 2004;63: 1009-14.

46. Hernandez-Perera O, Perez-Sala D, Soria E et al. Involvement of Rho GTPases in the transcriptional inhibition of preproendthelin-1 gene expression by simvastatin in vascular endothelial cells. Circ Res 2000;87: 616-22.

47. Hernandez-Perera O, Perez-Sala D, Navarro-Antolin J, et al. Effects of the 3hydroxy-3-methylglutaryl-CoA reductase inhibitors, atorvastatin and simvastatin, on the expression of endothelin-1 and endothelial nitric oxide synthase in vascular endothelial cells. J Clin Invest 1998;101: 2711-19.

48. Xu C, Stenman E, Edvinsson L. Reduction of bFGF-induced smooth muscle cell proliferation and endothelin receptor mRNA expression by mevastatin and atorvastatin. Biochem Pharm 2002;64: 497-505.

49. Ichiki T, Takeda K, Tokunou T, et al. Downregulation of angiotensin II type I receptor by hydrophobic 3-hydroxy-3-methylglutaryl coenzyme A reductase inhibitors in vascular smooth muscle cells. Arterioscler Thromb Vasc Biol 2001;21: 1896-901. 
50. Denton CP, Abraham DJ. Transforming growth factor-beta and connective tissue growth factor: key cytokines in scleroderma pathogenesis. Curr Opin Rheumatol 2001;13: 505-11.

51. Kim SI, Han DC, Lee HB. Lovastatin inhibits transforming growth factor$\beta 1$ expression in diabetic rat glomeruli and culture rat mesangial cells. J Am Soc Nephrl 2000;11: 80-7.

52. Li C, Yang CW, Park JH, et al. Pravastatin treatment attenuates interstitial inflammation and fibrosis in a rat model of chronic cyclosporine-induced nephropathy. Am J Physiol Rena Physiol 2004; 286: F46-F57.

53. Heusinger-Ribeiro J, Fischer B, Goppelt-Struebe M. Differential effects of simvastatin on mesangial cells. Kidney Int 2004;66: 187-95.

54. Goppelt-Struebe M, Hahn A, Rehm M, et al. Regulation of connective tissue growth factor (ccn $2 *$;ctgf) gene expression in human mesangial cells:modulation by HMGCoA reductase inhibitors (statins). J Clin Pathol Mol Pathol 2001;54: 176-79.

55. Eberlein M, Heusinger-Ribeiro J, Goppelt-Struebe M. Rho-dependent inhibition of the induction of connective tissue growth factor (CTGF) by HMG CoA reductase inhibitors (statins). Brit J Pharmacol 2001;133: 1172-80.

56. Danesh FR, Sadeghi MM, Amro N, et al. 3-Hydroxy-3-methylglutaryl CoA reductase inhibitors prevent high glucose-induced proliferation of mesangial cells via modulation of Rho GTPase/p21 signaling pathway: Implications for diabetic nephropathy. Proc Natl Acad Sci USA 2002;99: 8301-05. 
57. Tan A, Leverey H, Dahm C, et al. Lovastatin induces fibroblast apoptosis in vitro and in vivo; a possible therapy for fibroproliferative disorders. Am J Respir Crit Care Med 1999;159: 220-27.

58. Rombouts K, Kisanga E, Hellemans K, et al. Effect of HMG-CoA reductase inhibitors on proliferation and protein synthesis by rat hepatic stellate cells. J Hepatol 2003;38: 564-72.

59. Rosenbloom J, Saitta B, Gaidarova S, et al. Inhibition of type I collagen gene expression in normal and systemic sclerosis fibroblasts by a specific inhibitor of geranylgeranyl transferase I. Arthritis Rheum 2000;43: 1624-32.

60. Louneva N, Yan H, Huaman G, et al. Inhibition of collagen gene expression by statins in normal and systemic sclerosis $(\mathrm{SSc})$ dermal fibroblasts. Arthritis Rheum (abstract) 2004;50: S627

61. Del Papa N, Maglione W, Comina DP. Influence of atorvastatin on normal and scleroderma fibroblast activation and type I collagen production. Arthritis Rheum 2001;44: S193

62. Bourcier T, Libby P. HMG CoA reductase inhibitors reduce plasminogen activator inhibitor-1 expression by human vascular smooth muscle and endothelial cells. Arterioscler Thromb Vasc Biol 2000;20: 556-62.

63. Wiesbauer F, Kaun C, Zorn G, et al. HMG CoA reductase inhibitors affect the fibrinolytic system of human vascular cells in vitro: A comparative study using different statins. Br J Pharmacol 2002;135: 284-92. 
64. Laufs U, Marra D, Node K, et al. 3-Hydroxy-3-methylglutaryl-CoA reductase inhibitors attenuate vascular smooth muscle cell proliferation by preventing rho GTPase-induced down regulation of p27(Kip1). J Biol Chem 1999;273: 21926-31.

65. Wassmann S, Laufs U, Baumer AT, et al. Inhibition of geranylgeranylation reduces angiotensin II-mediated free radical production in vascular smooth muscle cells: Involvement of angiotensin AT1 receptor expression and Rac1 GTPase. Mol Pharmacol 2001;59: 646-54.

66. Huhle G, Abletshauser C, Mayer N, et al. Reduction of platelet activity markers in type II hypercholesterolemic patients by a HMG-CoA-reductase inhibitor. Thromb Res 1999;95: 229-34.

67. Seeger H, Mueck AO, Lippert TH. Fluvastatin increases prostacyclin and decreases endothelin production by human umbilical vein endothelial cells. Int J Pharmacol Ther 2000;38: 270-2. 
Figure 1. Mevalonate pathway of cholesterol biosynthesis.

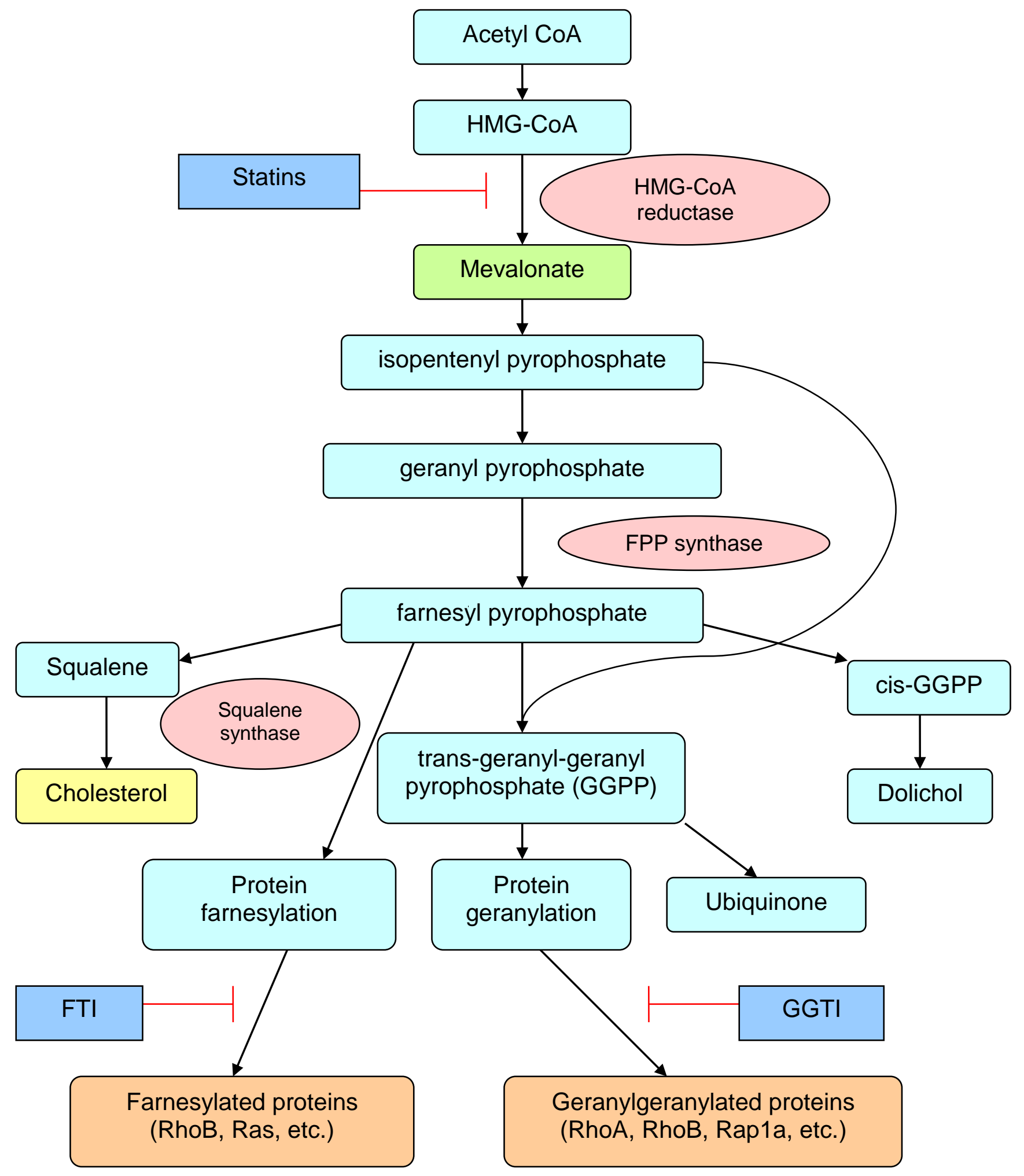


Key for Figure1:

FPP-farnesyl pyrophosphate

HMG CoA=hydroxyl-3-methylglutaryl Coenzyme A

GGPP=geranylgeranyl pyrophosphate

FTI=farnesyl transferase inhibitor

GGTI=geranylgeranyl transferase inhibitor 
Figure 2. Sites of potential action of statins on the pathogenesis of SSc vasculopathy.

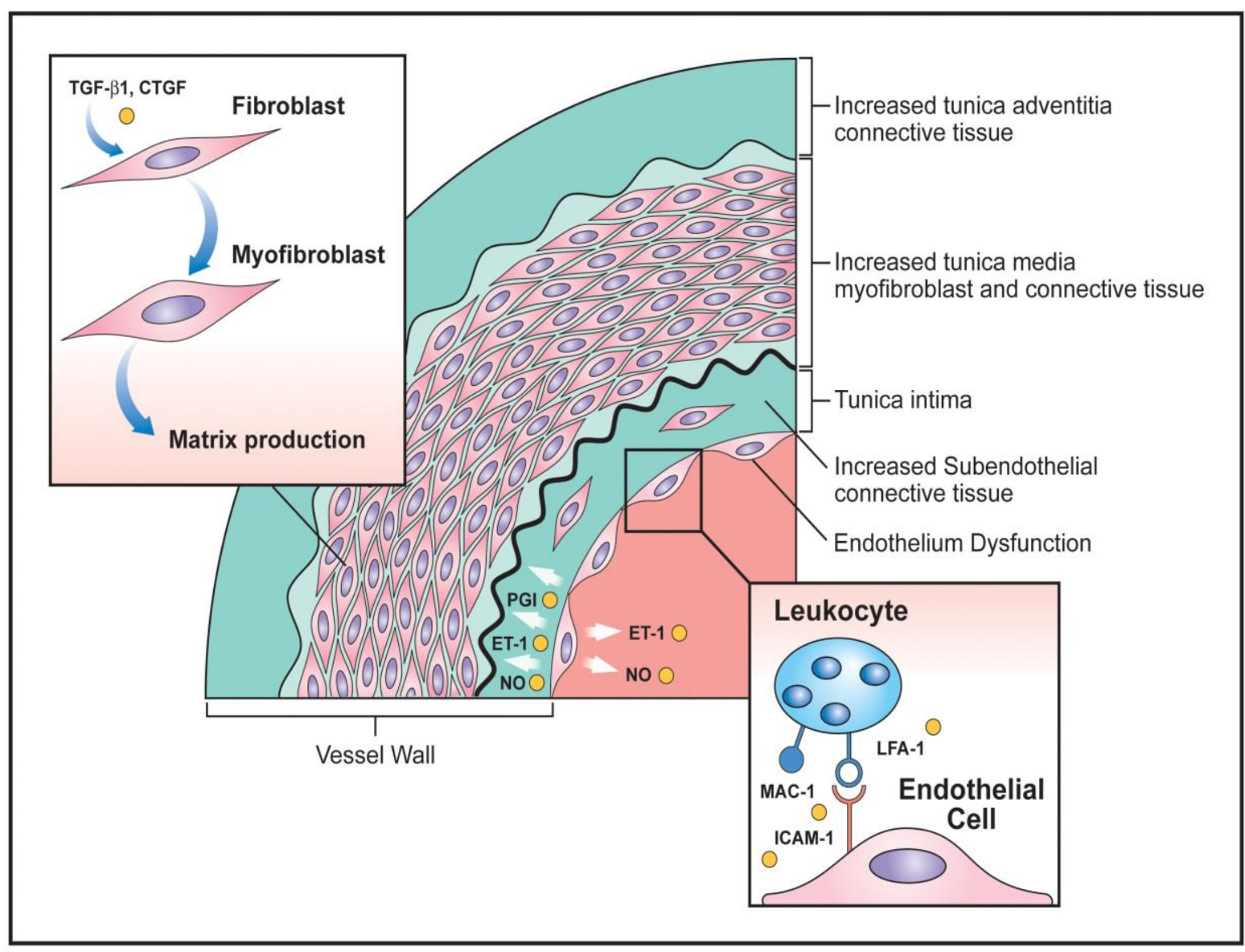


Key for Figure 2:

TGF- $\beta 1$ : transforming growth factor beta CTGF: connective tissue growth factor

PGI: prostacyclin

ET-1: endothelin-1

NO: nitric oxide

LFA-1: lymphocyte function associated antigen-1

ICAM-1: intercellular adhesion molecule-1

MAC-1: monocyte chemotactic protein-1

$\bigcirc$ : Sites of potential action of statins 